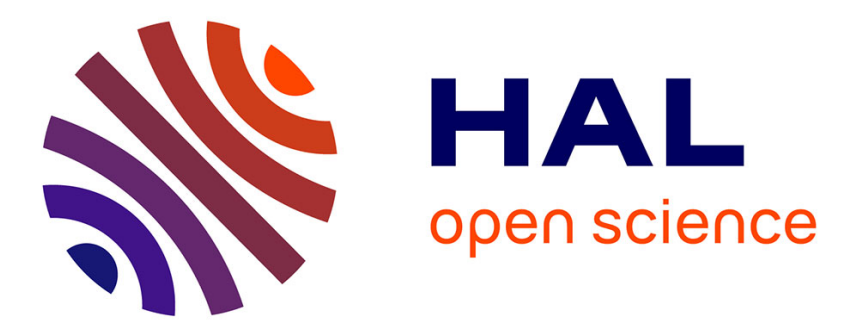

\title{
The purification of SF6 in a constant temperature adsorption process
}

\author{
C. Brassard
}

\section{To cite this version:}

C. Brassard. The purification of SF6 in a constant temperature adsorption process. Revue de Physique Appliquée, 1977, 12 (10), pp.1423-1425. 10.1051/rphysap:0197700120100142300 . jpa-00244340

HAL Id: jpa-00244340 https://hal.science/jpa-00244340

Submitted on 1 Jan 1977

HAL is a multi-disciplinary open access archive for the deposit and dissemination of scientific research documents, whether they are published or not. The documents may come from teaching and research institutions in France or abroad, or from public or private research centers.
L'archive ouverte pluridisciplinaire HAL, est destinée au dépôt et à la diffusion de documents scientifiques de niveau recherche, publiés ou non, émanant des établissements d'enseignement et de recherche français ou étrangers, des laboratoires publics ou privés. 


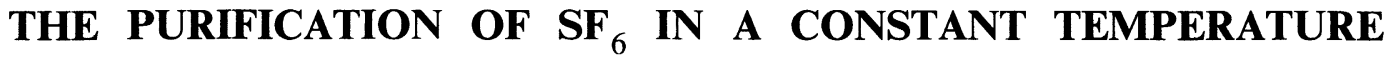 ADSORPTION PROCESS
}

\author{
C. BRASSARD
}

\begin{abstract}
Laboratoire de Physique Nucléaire, Université de Montréal, 2905, Marie Guyard, Montréal, Québec H3C 3J7, Canada
\end{abstract}

\begin{abstract}
Résumé. - Le $\mathrm{SF}_{6}$ du Dynamitron et celui du Tandem, contenant respectivement $11 \%$ et $35 \%$ d'impuretés non-condensables, a été purifié à mieux que $99,9 \%$ par une machine utilisant le ralentissement de la propagation du $\mathrm{SF}_{6}$ dû à son adsorption dans une colonne de charbon actif à une température constante de $-20^{\circ} \mathrm{C}$.

Abstract. - The Dynamitron and the Tandem $\mathrm{SF}_{6}$ gas, initially contained $11 \%$ and $35 \%$ noncondensable impurities, respectively. The gas has been purified to better than $99.9 \%$, using a constant temperature dynamic batch process, where the $\mathrm{SF}_{6}$ propagation is simply delayed in an activated charcoal column at $-20^{\circ} \mathrm{C}$.
\end{abstract}

1. Introduction. - The sulphur hexafluoride $\left(\mathrm{SF}_{6}\right)$ gas used as an insulating medium in electrostatic accelerators is expensive and readily contaminated with air during gas transfer cycles. The problem of removing air contamination from $\mathrm{SF}_{6}$ is therefore of general interest to such installations. The high vapour pressure of liquid $\mathrm{SF}_{6}$ (minimum 2.24 bar) and its miscibility with air impair the conventional methods such as distillation. Pioneering work at Chalk River, by N. Burn and P. Hurley has led to the first practical method of purification, using liquid nitrogen to freeze the $\mathrm{SF}_{6}$.

An additional contamination with helium, which had to be removed to below the part per million level in order to run the Dynamitron, prevented us to use the freezing method. The new technique described herein was used successfully to purify the Dynamitron gas, which contained initially $11 \%$ air and $35 \mathrm{ppm}$ helium, and the Tandem gas, which contained $34 \%$ air and $1 \%$ helium. The final purities are better than $99.9 \%$, and the $\mathrm{SF}_{6}$ losses amount to $1 \%$ and $5 \%$ respectively.

2. Description of the purification system. - Figure 1 is a simplified block diagram of the purification system, which consists basically of an activated charcoal column and two valves, V3 and V4, which open successively to collect the separated non-condensable gases and $\mathrm{SF}_{6}$.

The completely automatic cycle runs as follows. A batch of 75 atmosphere-liter of mixture (approximately 500 grams) is introduced in two seconds into the

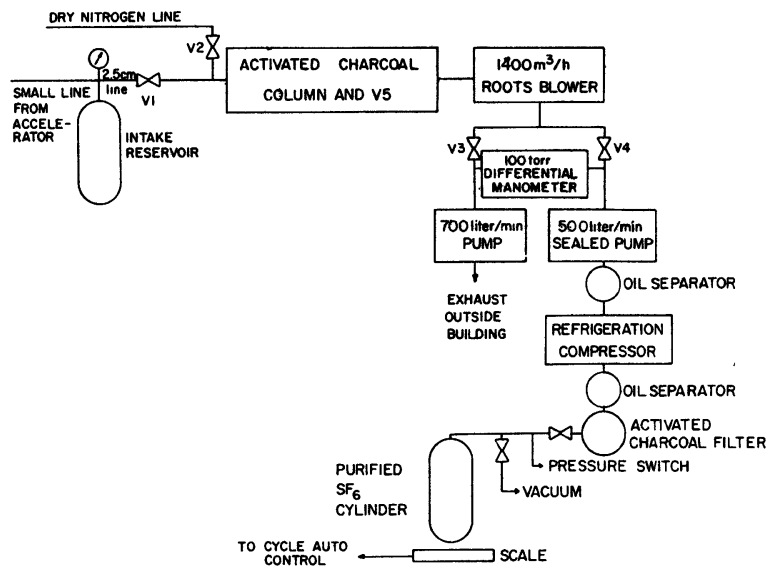

FIG. 1. - Simplified block diagram of the $\mathrm{SF}_{6}$ purification system. Valves V1, V3, V4 and V5 are opened and closed sequentially by the automatic cycle control; the pumps and the compressor run continuously.

column intake through V1. The non-condensable gas pressure appears at the exhaust within five seconds, and is evacuated to the atmosphere through the Roots blower, V3, and a mechanical pump. After 100 seconds, the pressure starts to rise again, indicating the arrival of $\mathrm{SF}_{6}, \mathrm{~V} 3$, then closes, while $\mathrm{V} 4$ opens, allowing the collection of $\mathrm{SF}_{6}$ in a cylinder, through the same Roots blower, V4, a sealed mechanical pump, a normal refrigeration compressor and an oil vapour filter. At the end of the fifteen minute period, V3 opens, V4 closes, and the cycle is repeated.

Figure 2 shows the assembled system. Various pressure switches, overpressure protection devices and 


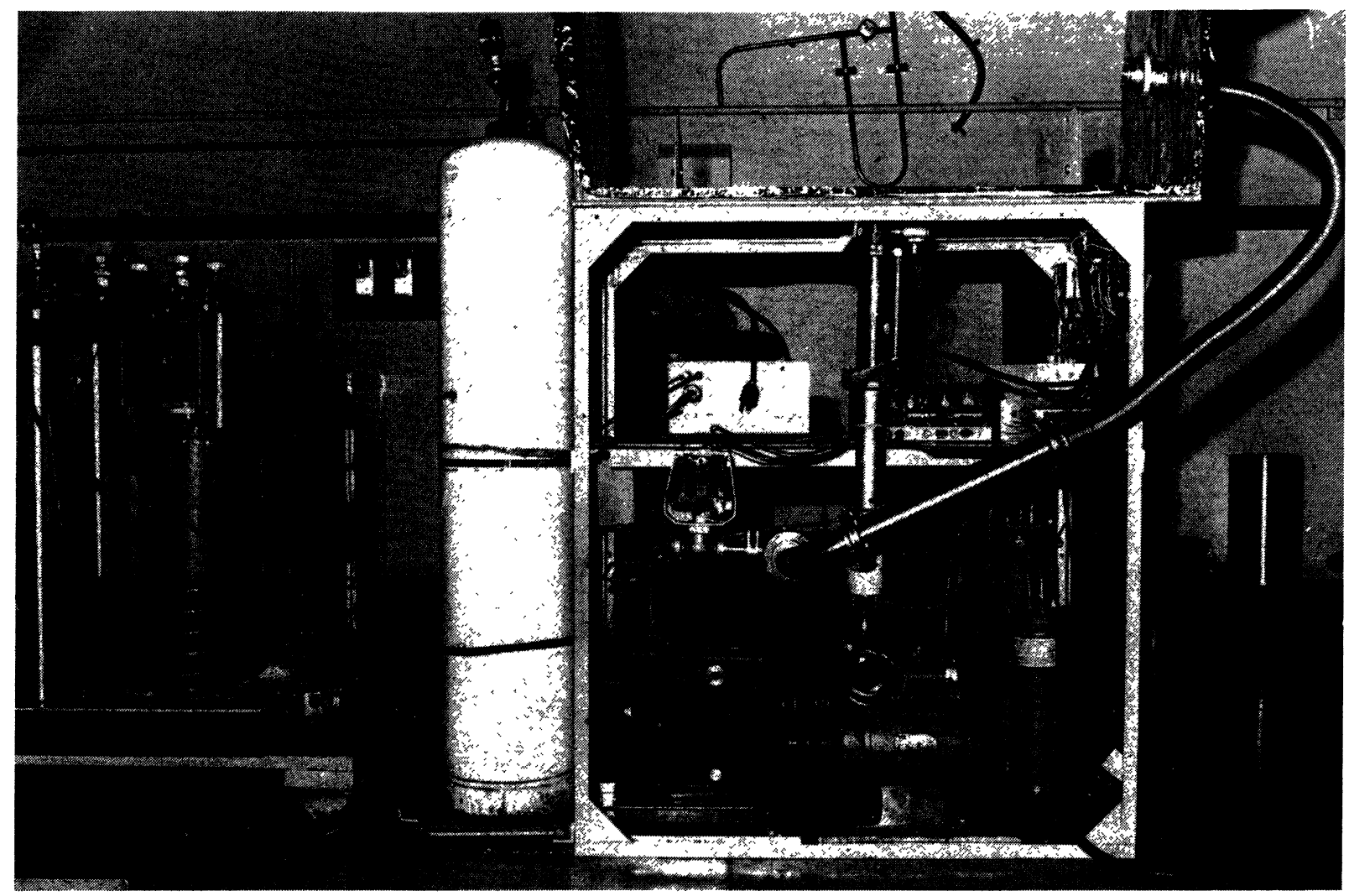

FIG. 2. - View of the completed $\mathrm{SF}_{6}$ purification system, without the column itself, which fits in the box on top. The refrigeration system sits on the left hand side.

relays have been installed as a protection against power or mechanical failures; they are omitted from figure 1. The liquefaction of $\mathrm{SF}_{6}$ is achieved by running water over the cylinder. The system stops automatically when the normal $\mathrm{SF}_{6}$ charge is attained, which corresponds to a cylinder approximately halffilled, as detected by an automatic scale. For safety, the cylinder should never be filled with liquid, the expansion of which can cause overpressure.

Prior to the first run, the activated charcoal column is baked under vacuum, with a $50 \mathrm{mbar}$. liter/second dry nitrogen purge. The activated charcoal in the filter which follows the compressor is changed periodically to ensure oil-free $\mathrm{SF}_{6}$. The column itself does not need to be changed nor reactivated under normal conditions.

3. Construction of the column. - The column is an aluminium cylinder $200 \mathrm{~mm}$ in diameter, and $840 \mathrm{~mm}$ long. It is packed tightly with randomly oriented expanded aluminium discs, with 20 to 40 mesh ( $850 \mu \mathrm{m}$ to $425 \mu \mathrm{m}$ size) activated charcoal filling the interstices. The aluminium provides the heat conduction and exchanges locally with the charcoal the heat of adsorption; the ratio is two volumes of charcoal for one volume of metal. The insulated column is maintained at a constant temperature of $-20^{\circ} \mathrm{C}$, using a conventional refrigeration system driven by a 250 watt motor.
A ten-stage valve of special design, V5, is fitted axially in the column, and is operated from the outside with a compressed air cylinder, through a bellows. When the valve is closed, the column acts as a full length column. During the purified $\mathrm{SF}_{6}$ recuperation, however, this valve is opened and permits the simultaneous, parallel pumping of ten column sections through the axis.

4. Results and discussion. - Figure 3 shows the pressure measured at $\mathrm{V} 3$ as a function of time; excep-

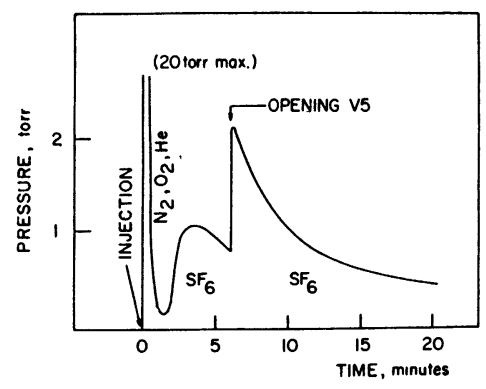

Fig. 3. - Pressure at the inlet of the mechanical pump, as a function of time during a complete cycle. The deep valley between the non-condensable peak and the $\mathrm{SF}_{6}$ peak shows that they are well separated. V5 is an axial valve, internal to the column, which is described in the text. The charge was 520 grams of mixture containing $11 \%$ non-condensable gases. 
tionally, V3 was kept open and V4 closed during the complete cycle, in order to keep a positive reading from the MKS Baratron differential capacitance manometer. The rise in pressure due to the arrival of $\mathrm{SF}_{6}$ and the increased throughput upon opening V5 are clearly seen. A charge of 520 grams was injected in this particular batch, corresponding to a production rate of 45 kilograms of purified $\mathrm{SF}_{6}$ per day.

The system described herein requires relatively little energy to effect the separation. In practice, the energy needed is only that which is required to keep the pumps running. Accelerator shut down can be prevented by continuously reinjecting the purified $\mathrm{SF}_{6}$ into the accelerator.

The equipement needed to build the system is readily available in most nuclear physics laboratories. The obvious disadvantage is the relative complexity of the system. 